\title{
ANALISE DA INCIDÊNCIA DE SUPRESSÃO ARBÓREA E SUAS PRINCIPAIS CAUSAS NO PERÍMETRO URBANO DO MUNICÍPIO DE ITAPIRA-SP
}

\author{
Anderson Martelli ${ }^{1}$; Joaquim Barbosa Junior ${ }^{2}$ \\ (recebido em 25.06.2010 e aceito para publicação em 15.12.2010)
}

\section{RESUMO}

Por falta de um planejamento, o plantio de árvores em vias públicas tem gerado problemas aos moradores, o que tem aumentado os pedidos de supressão. Esse trabalho tem por objetivo realizar uma análise quantitativa das causas que determinaram a supressão de árvores e as regiões de maior incidência desses cortes no período de Janeiro de 2009 a Dezembro de 2009 dentro do perímetro urbano no município de Itapira-SP. Para isso realizou-se um levantamento de dados na Secretaria de Agricultura e Meio Ambiente (SAMA) do município, responsável pelas autorizações de corte. Os resultados demonstraram que foram suprimidas 119 árvores, sendo que a Vila Izaura foi o bairro com o maior número de arvores cortadas - 14 unidades. Na análise quantitativa das espécies suprimidas, ficou constatado que o Ficus benjamina foi a espécie de maior ocorrência, 25 indivíduos. Quanto aos motivos de supressão dessas árvores, nas causas isoladas, 104 árvores foram suprimidas, sendo o risco de queda o principal motivo desses cortes - 22 supressões. Nas supressões que ocorreram por dois motivos, 15 árvores foram suprimidas, onde a) rachaduras na calçada/tronco doente e b) árvores impróprias para calçadas/rachaduras na calçada responderam pelo corte de 5 árvores cada - 33,33\% respectivamente.

Palavras-chave: arborização urbana, risco de queda, rachaduras na calçada.

\footnotetext{
${ }^{1}$ Biólogo, Prefeitura Municipal de Itapira, Secretaria de Agricultura e Meio Ambiente, Itapira, São Paulo, martellibio@hotmail.com

${ }_{2}^{2}$ Administrador e Secretário, Prefeitura Municipal de Itapira, Secretaria de Agricultura e Meio Ambiente, Itapira, São Paulo, joaquim.barbosa@itapira.sp.gov.br
} 


\section{ANALYSIS OF THE INCIDENCE OF TREE SUPPRESSION AND ITS MAIN CAUSES IN THE URBAN PERIMETER OF THE TOWN OF ITAPIRA-SP}

\section{ABSTRACT}

Due to lack of planning, planting trees on the streets has caused problems for local residents, so the requests for their suppression have increased. This paper aims to perform a quantitative analysis of the causes that led to the suppression of trees and the areas of higher incidence of tree cutting from January to December 2009 within the urban perimeter of the town of Itapira-SP. For doing this, we carried out a data collection in Itapira's Department of Agriculture and Environment (SAMA), responsible for cutting permits. The results showed that 119 trees were cut; Vila Izaura was the neighborhood with the largest number of trees cut down - 14 units. In the quantitative analysis of the species suppressed it was found that the Ficus benjamina was the most affected species, with 25 individuals. Regarding the reasons for suppressing these trees, isolated causes led to the removal of 104 trees, being the falling risk the main reason - 22 units. The suppressions due to two reasons achieved 15 trees, where a) sidewalk cracks/ill trunk and b) trees unfit for sidewalks/sidewalk cracks led to the cut of five trees each $-33.33 \%$ respectively.

Keywords: urban tree planting, falling risk, sidewalk cracks. 


\section{INTRODUÇÃO}

A árvore é a forma vegetal mais característica na paisagem urbana, a qual, ao longo da história, tem se incorporado em estreita relação com a arquitetura das cidades. A arborização urbana contribui para obtenção de um ambiente urbano agradável e tem influência decisiva na qualidade de vida nas cidades e, portanto, na saúde da população. A importância da árvore, no meio urbano, ganha relevância maior, principalmente quando a concentração das habitações aumenta (MÜLLER, 1998).

A arborização urbana em vias públicas é fundamental para manutenção da qualidade de vida, proporcionando conforto aos habitantes das cidades, pois contribui com a estabilização climática, embeleza, fornece abrigo e alimento à fauna e sombra e lazer às ruas e avenidas das cidades (GRAZIANO, 1994; SILVA FILHO et al., 2002; RODOLFO JUNIOR et al, 2008; COLETO et al., 2008).

Em estudos de Alves e Gouveia (1995), destaca-se que as propriedades que ficavam próximas às áreas arborizadas eram mais valorizadas, apresentavam um baixo índice de mudança de residência e que as folhagens são um tema dominante na memória das crianças que moravam na cidade. Isto foi explicado pelos benefícios propiciados pelas árvores como: aumento da diversidade sensorial, diminuição do vandalismo, redução do consumo de energia e a satisfação dos moradores com as residências.

A arborização urbana no Brasil é de competência das administrações municipais. Embora haja uma crescente disposição, tanto dos órgãos governamentais envolvidos, como de grande parcela da população, muitos são os problemas enfrentados, como a falta de técnicos capacitados que orientem sobre um plantio correto, escolha da espécie, poda de formação, utilização de tutores, grade de proteção, irrigação em período de estiagem e adubação (RIBEIRO, 2009).

Segundo Bortoleto, Silva Filho e Lima (2006), muitas cidades brasileiras não possuem um planejamento adequado de arborização urbana, muitos projetos baseiam-se em métodos puramente empíricos, desprovidos de um conhecimento real do assunto.

Assim, para alcançar a qualidade do ambiente urbano é necessário realizar um planejamento prévio. Contudo, quando não há planejamento desta arborização, inúmeros problemas podem ocorrer e ao invés de um elemento benéfico, a arborização passa a representar um foco de conflito nas cidades (COLETO et al., 2008).

De acordo com Teixeira (1999) e Rodrigues (2002) as cidades são todas iguais possuindo vários, senão todos os elementos e características em comum: sistema viário (m) $m$

$\mathbf{S} \cdot \mathbf{B} \cdot \mathbf{A} \cdot \mathbf{U}$ Soc. Bras. de Arborização Urbana 
(estruturado ou não); espaços residenciais; espaços comerciais e de serviço; espaços industriais; espaços institucionais; espaços livres ou abertos. E a julgar tanto pela forma universalizante do tratamento das questões urbanas quanto pelas normas gerais que regem a urbanização no Brasil, a começar pelos códigos de postura municipais e leis de loteamentos, é de considerar-se que as cidades, em todos os lugares, sejam mesmo muito parecidas.

Dessa forma, planejar a arborização é indispensável para o desenvolvimento urbano e requer, antes de qualquer coisa, o conhecimento da situação existente, o que pode ser conseguido através de um inventário quali-quantitativo, assim como o conhecimento das características dos vegetais que poderão ser utilizados (COLETO et al., 2008).

Atualmente a gestão da arborização urbana no município de Itapira - SP é de responsabilidade da Secretaria de Agricultura e Meio Ambiente, órgão vinculado à Prefeitura Municipal, que através da vistoria de seus técnicos dão parecer favorável ou não a supressão da arborização urbana do município.

O objetivo deste trabalho foi realizar um estudo transversal com o levantamento de dados nos arquivos deste órgão quanto às solicitações de corte de arvores deferidos dentro do perímetro urbano e os bairros de maior incidência no município de Itapira referente o ano de 2009.

Levando em consideração a importância da arborização para o bem estar da população e a grande escassez de informações sobre os motivos que levam os moradores de uma cidade a solicitar de forma exacerbada supressões de arvores nos espaços urbanos, este trabalho vem levantar as principais causas de supressão da arborização urbana de Itapira permitindo o planejamento de uma arborização que valorize o aspecto paisagístico ecológico com a utilização de espécies adequadas e compatíveis com as características físicas da cidade.

\section{MATERIAIS E MÉTODOS}

\section{Caracterização do Município de Itapira}

O Município de Itapira integra a Região Administrativa de Campinas (figura 1) e está localizado na região Sudeste, porção centro-leste do Estado de São Paulo, a 22 '26'10" de latitude S e 46²'18"de longitude W, distando aproximadamente $63 \mathrm{~km}$ (via anel de contorno) da cidade de Campinas e $159 \mathrm{~km}$ da capital do Estado.

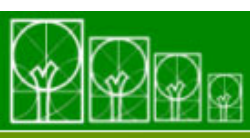

S $\cdot \mathbf{B} \cdot \mathbf{A} \cdot \mathbf{U}$ Soc. Bras. de Arborização Urbana 
Possui uma área de $517,5 \mathrm{~km}^{2}$, com uma estimativa populacional de 71.850 habitantes. O perímetro urbano alvo do estudo apresenta uma área de $58.042 \mathrm{~m}^{2} \mathrm{com}$ uma densidade demográfica de 132,2 habitantes por km² (IBGE, 2009). Segundo dados do setor de Lançadoria da Prefeitura (2008) esta área conta hoje com 20.600 imóveis.

As primeiras indústrias do município foram relacionadas à ferrovia e à base da agricultura local e regional por meio de fábricas de implementos agrícolas. Atualmente a atividade industrial de Itapira é representada pelas indústrias de embalagens de papelão, brinquedos, mecânica, máquinas e implementos agrícolas, transformação de madeira e marcante presença de usina de açúcar e álcool e atividades extrativista mineral.

O saneamento básico de Itapira é um dos maiores referenciais do município. Hoje, $100 \%$ dos imóveis urbanos recebem água tratada e têm seu esgoto 100\% coletado e tratado, com eficiência de $82 \%$ após passar pelo sistema de lagoas aeróbica e anaeróbica.

Figura 1- Localização do Município de Itapira no Estado de São Paulo e na Região de Governo de Campinas.

Figure 1 - Location of the town of Itapira in Sao Paulo State and the Region of Campinas's Administration.

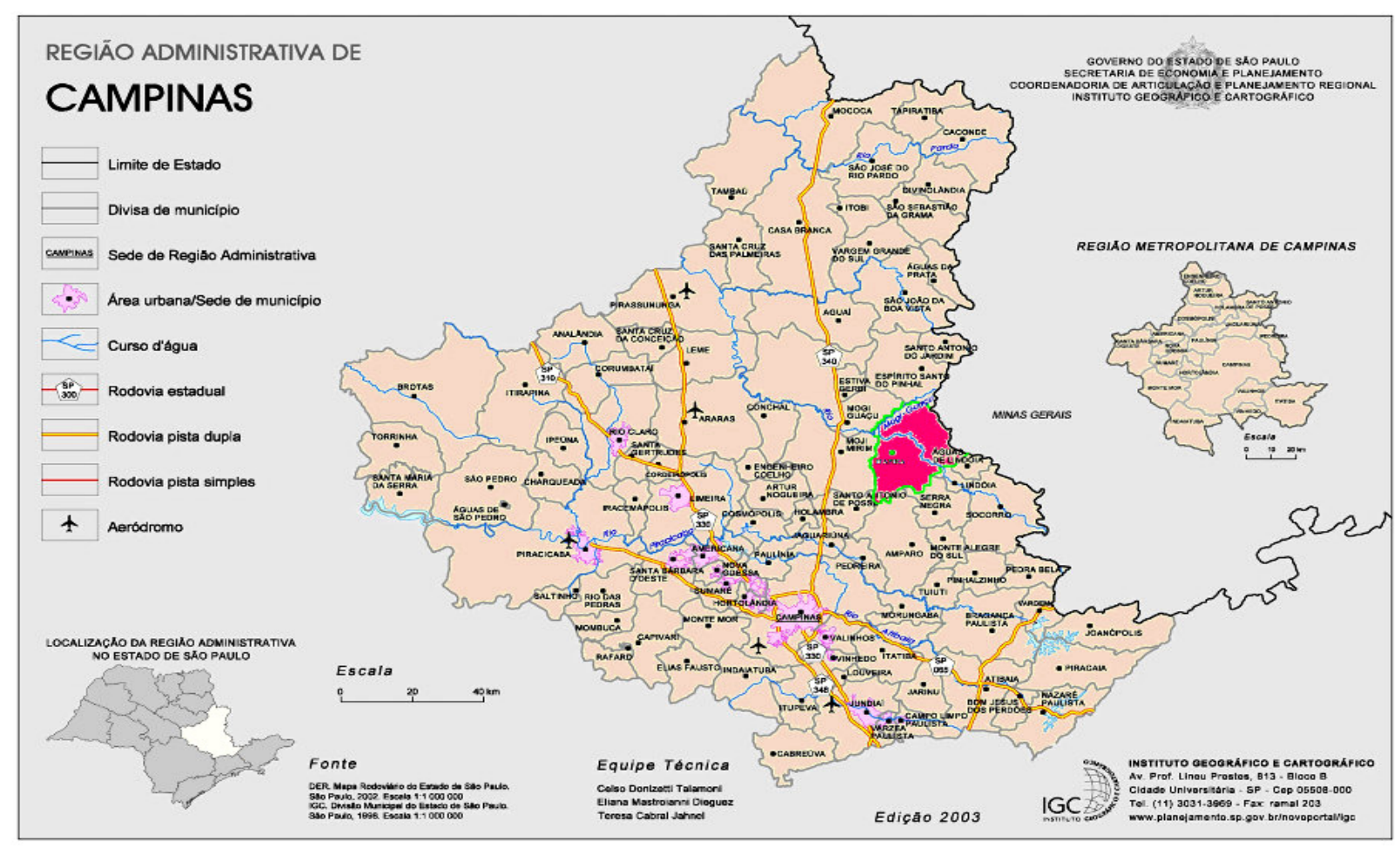


Acha-se incluído na "Serrania de Lindóia", segundo subdivisão geomorfológica do Estado de São Paulo proposta no Mapa Geomorfológico do Estado de São Paulo (IPT, 2006). Limita-se a oeste, com a "Zona do Mogi Guaçu", uma das três subdivisões propostas para as Depressões Periféricas Paulista, representadas pelas rochas da Bacia do Paraná.

O clima predominante na região é o Temperado Quente Úmido, de acordo com classificação de Köppen, havendo estações com mais de 60 dias secos, com temperatura máxima anual em cerca de $29^{\circ} \mathrm{C}$ e temperatura mínima anual em cerca de $5^{\circ} \mathrm{C}$, com médias anuais de precipitação em torno de 1.600 mm (SETZER,1976).

\section{Levantamento Quantitativo dos Dados}

As supressões arbóreas no município de Itapira - SP são realizadas iniciando com uma vistoria de técnicos da Secretaria de Agricultura e Meio Ambiente, o qual após criteriosa inspeção é preenchido um laudo "Solicitação de Corte de Arvore" sobre as condições fitossanitárias e biomecânicas e/ou relatando o motivo da supressão da espécie caso seja deferido o corte da mesma pelo técnico.

Diante deste procedimento, foi realizada uma analise exploratória de dados nos arquivos da Secretaria de Agricultura e Meio Ambiente de Itapira - SP quanto as solicitações de corte de arvores deferidos dentro do perímetro urbano do município de Itapira no período de janeiro de 2009 a dezembro de 2009.

Os dados analisados neste levantamento foram: localização das árvores suprimidas no município (número de árvores/bairro), espécies e quantidades suprimidas e os motivos que determinaram a supressão dessas árvores, levando em consideração as anotações realizadas nos laudos técnicos.

\section{RESULTADOS E DISCUSSÃO}

Segundo os dados pesquisados no período de janeiro de 2009 a dezembro de 2009 foram autorizados pelos técnicos da Secretaria de Agricultura e Meio Ambiente a supressão de 119 exemplares arbóreos distribuídos em 29 bairros do município conforme demonstrado na tabela 1 . 
Tabela 1: Distribuição de árvores suprimidas por bairro do município de Itapira no ano de 2009.

Table 1: Distribution of trees suppressed by neighborhood of the town of Itapira in 2009.

\begin{tabular}{|c|c|c|}
\hline Bairros & $\mathrm{n}$ - árvores suprimidas & F (\%) \\
\hline Prados & 8 & 6,72 \\
\hline Santa Cruz & 9 & 7,56 \\
\hline José Secchi & 2 & 1,68 \\
\hline Della Rocha 2 & 2 & 1,68 \\
\hline São Vicente & 2 & 1,68 \\
\hline Assad Alcici & 6 & 5,04 \\
\hline Centro & 3 & 2,52 \\
\hline Braz Cavenaghi & 1 & 0,84 \\
\hline Vila Izaura & 14 & 11,77 \\
\hline Santa Fé & 6 & 5,05 \\
\hline Figueiredo & 4 & 3,36 \\
\hline Nosso Teto & 4 & 3,36 \\
\hline Boa Esperança & 5 & 4,20 \\
\hline Nova Itapira & 9 & 7,56 \\
\hline Pé no Chão & 2 & 1,68 \\
\hline Flavio Zacchi & 7 & 5,88 \\
\hline Penha do Rio do Peixe & 6 & 5,04 \\
\hline Santa Marta & 13 & 10,92 \\
\hline Vila Ilze & 3 & 2,52 \\
\hline Jardim Raquel & 3 & 2,52 \\
\hline Jardim Galego & 1 & 0,84 \\
\hline Vila Pereira & 1 & 0,84 \\
\hline Jardim Guarujá & 2 & 1,68 \\
\hline Bela Vista & 1 & 0,84 \\
\hline Jardim Itamaracá & 1 & 0,84 \\
\hline Vila Kennedy & 1 & 0,84 \\
\hline Jardim Magali & 1 & 0,84 \\
\hline Aquiles Galdi & 1 & 0,84 \\
\hline Cubatão & 1 & 0,84 \\
\hline Total & 119 & $100 \%$ \\
\hline
\end{tabular}

Da análise do número de árvores suprimidas em relação a sua localização (bairro), foi possível observar que o bairro Vila Izaura apresentou a maior incidência de árvores cortadas - 14 unidades, respondendo por $11,77 \%$, seguido pelo bairro Santa Marta com 13 árvores - 10,92\%.

$\mathrm{Na}$ análise quantitativa das espécies suprimidas, do total de 119 árvores distribuídas em 17 famílias, o Ficus benjamina da família Moracea foi a espécie de maior ocorrência, 25 
indivíduos respondendo por $21 \%$ dos cortes, seguido pelo Ligustrum lucidum encontrado na família Oleaceae 21 indivíduos, representando 17,25\% e a Caesalpinia peltphoroides com a supressão de 17 indivíduos - 14,29\% conforme descrito na tabela 2.

Tabela 2: Relação das espécies arbóreas suprimidas no município de Itapira no ano de 2009.

Table 2: List of suppressed tree species in the town of Itapira in 2009.

\begin{tabular}{|c|c|c|c|c|}
\hline Família e Espécie & Nome Popular & $\begin{array}{l}\text { Origem } \\
\text { (1) }\end{array}$ & $\begin{array}{c}\text { № de } \\
\text { indivíduos }\end{array}$ & Freq (\%) \\
\hline $\begin{array}{c}\text { LEGUMINOSAE- } \\
\text { CAESALPINIOIDEAE } \\
\text { Cassia ferruginea }\end{array}$ & Cássia & $\mathrm{N}$ & 1 & 0,84 \\
\hline Pterogyne nitens & Amendoim-bravo & $\mathrm{N}$ & 1 & 0,84 \\
\hline Delonix regia & Flamboyant & $E$ & 3 & 2,52 \\
\hline $\begin{array}{l}\text { MELASTOMATACEAE } \\
\text { Tibouchina candolleana }\end{array}$ & Quaresmeira & $\mathrm{N}$ & 5 & 4,20 \\
\hline $\begin{array}{l}\text { MORACEAE } \\
\text { Ficus benjamina }\end{array}$ & Fícus & $E$ & 25 & 21,0 \\
\hline $\begin{array}{c}\text { OLEACEAE } \\
\text { Ligustrum lucidum }\end{array}$ & Alfeneiro & $E$ & 21 & 17,65 \\
\hline $\begin{array}{c}\text { BIGNONIACEAE } \\
\text { Tabebuia heptaphylla }\end{array}$ & Ipê Roxo & $\mathrm{N}$ & 2 & 1,68 \\
\hline Tabebuia chrysotricha & Ipê Amarelo & $\mathrm{N}$ & 2 & 1,68 \\
\hline $\begin{array}{c}\text { LEGUMINOSAE } \\
\text { Caesalpinia peltphoroides }\end{array}$ & Sibipiruna & $\mathrm{N}$ & 17 & 14,29 \\
\hline Bauhinia longifolia & Pata de Vaca & $E$ & 3 & 2,52 \\
\hline Leucaena leucocephafa & Leucena & $E$ & 1 & 0,84 \\
\hline $\begin{array}{l}\text { MAGNOLIACEAE } \\
\text { Michelia champaca }\end{array}$ & Magnólia & $E$ & 1 & 0,84 \\
\hline- & Não identificada & - & 7 & 5,88 \\
\hline $\begin{array}{c}\text { LYTHRACEAE } \\
\text { Lagerstroemia indica }\end{array}$ & Resedá & $E$ & 1 & 0,84 \\
\hline $\begin{array}{c}\text { ARACACEAE } \\
\text { Syagrus romanzoffiana }\end{array}$ & Jerivá & $\mathrm{N}$ & 1 & 0,84 \\
\hline $\begin{array}{l}\text { RUTACEAE } \\
\text { Murraya exotica }\end{array}$ & Murta & $E$ & 1 & 0,84 \\
\hline $\begin{array}{l}\text { ANACARDIACEAE } \\
\text { Shinus mole }\end{array}$ & Aroeira Salsa & $\mathrm{N}$ & 2 & 1,68 \\
\hline $\begin{array}{c}\text { LAURACEAE } \\
\text { Nectandra megapotamica }\end{array}$ & Canelinha & $\mathrm{N}$ & 6 & 5,04 \\
\hline $\begin{array}{l}\text { PINACEAE } \\
\text { Pinus elliottii }\end{array}$ & Pinus & $E$ & 11 & 9,25 \\
\hline ANACARDIACEAE & Mangueira & & 1 & \\
\hline
\end{tabular}




\begin{tabular}{c|c|c|c|c}
\hline Maganifera indica & & $\mathrm{E}$ & & 0,84 \\
\hline $\begin{array}{c}\text { MYRTACEAE } \\
\text { Callistemon viminalis }\end{array}$ & Escova de Garrafa & $\mathrm{E}$ & 1 & 0,84 \\
\hline $\begin{array}{c}\text { Eucalyptus ficifolia } \\
\text { COMBRETACEAE } \\
\text { Terminalia catappa }\end{array}$ & Eucalipto Vermelho & $\mathrm{E}$ & 4 & 3,36 \\
\hline TOTAL & Chapéu de Praia & $\mathrm{E}$ & 2 & 1,68 \\
\hline
\end{tabular}

(1) $\mathrm{E}=$ Exótica, $\mathrm{N}=$ Nativa. $/ \mathrm{E}=$ Exotic, $\mathrm{N}=$ Native.

Os resultados demonstrados neste estudo corroboram com os dados de Santana e Santos (1999), onde relatam que o Fícus benjamina é uma das arvores mais prejudicial ao calçamento e à estrutura viária da cidade, e o gênero Ficus é causador de grandes problemas como elemento de arborização no Campus da Universidade Estadual de Feira de Santana (UEFS), por danificar calçadas.

Rossetti et al (2010) e Almeida e Barbosa (2010) ressaltam que diversos gêneros de Ficus spp. mostraram ser de porte desproporcional ao plantio em calçadas, tendo contato direto com a rede elétrica, pondo em risco a vida humana durante a poda ou uma descarga elétrica durante chuvas e obstruindo a visão dos condutores de veículos.

Estes problemas são muito comuns de serem visualizados e causam, na maioria das vezes, um manejo inadequado e prejudicial às árvores podendo levar em ultimo caso a sua erradicação.

Quanto aos principais motivos descritos pelos técnicos do SAMA que levaram a supressão das 119 árvores no ano de 2009, o estudo demonstrou que dentre os motivos isolados, foram suprimidas 104 árvores, sendo o risco de queda a principal causa desses cortes respondendo por 22 supressões $(21,15 \%)$, seguido de construção e reforma de casas, muros ou mudanças na arquitetura da residência, sendo suprimidos 17 exemplares (16,35\%) e árvores impróprias para calçadas 13 exemplares, representando 12,5\%, figura 2.

Assim, é possível observar que dentre os três motivos isolados - risco de queda, construção e reforma e árvores impróprias para calçadas representaram $50 \%$ dos cortes deferidos (52 árvores) em 2009. As demais causas isoladas que levaram a supressão dos outros $50 \%$ podem ser visualizados na figura 2 . 


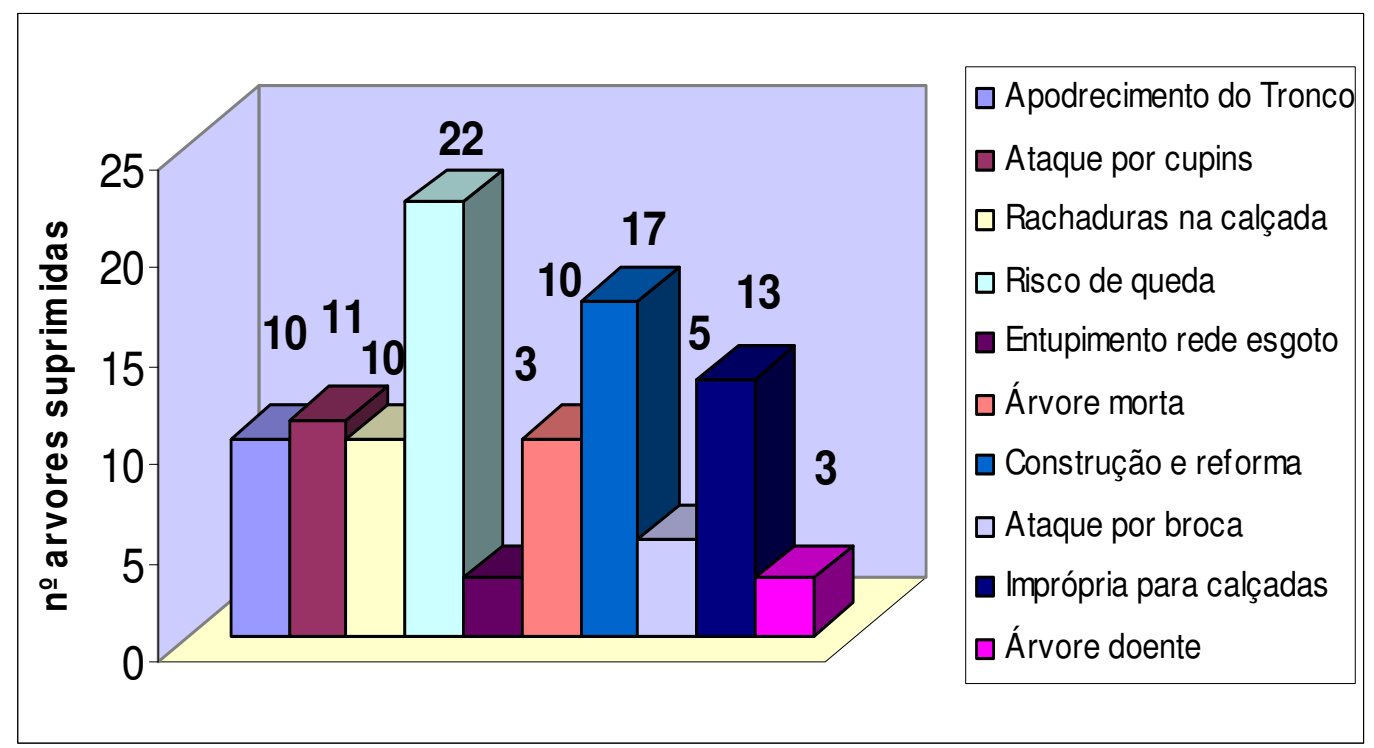

Figura 2: Motivos isolados de supressão de árvores no Município de Itapira-SP ocorrido em 2009.

Figure 2: Isolated reasons for the removal of trees in the town of Itapira-SP in 2009.

O número de árvores suprimidas por serem impróprias para calçada foi bastante significativo corroborando com o estudo de Rossetti et al (2010), onde relata que as espécies adequadas para serem usadas nas calçadas ainda são muito pouco estudadas no Brasil.

De acordo com Ribeiro (2009), o plantio de árvores inadequadas à estrutura urbana gera conflitos com equipamentos urbanos como fiações elétricas, encanamentos, calhas, calçamentos, muros, postes de iluminação, etc.

Segundo Silva et al (2002) somente no ano de 1999, em Uberlândia, foram solicitados 808 pedidos de cortes de árvores, que tinham como justificativa algum tipo de conflito com a rede elétrica, danos ao imóvel, danos nas calçadas e folhas que caem e provocam incômodos.

$\mathrm{Na}$ análise das supressões que ocorreram por fatores associados, foi observada a supressão de 15 árvores, onde rachadura na calçada/tronco doente e árvores impróprias para calçadas/rachaduras na calçada responderam pelo corte de 5 árvores cada $-33,33 \%$ respectivamente.

Ataques por cupins e rachaduras na calçada levaram ao corte de 3 exemplares $20 \%$, e o entupimento de esgoto/apodrecimento do tronco e ataque por broca/apodrecimento do tronco tiveram 2 árvores cortadas, resultando em $6,66 \%$ cada conforme demonstrado na figura 3.

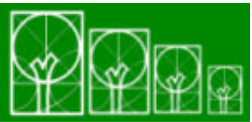

$\mathbf{S} \cdot \mathbf{B} \cdot \mathbf{A} \cdot \mathbf{U}$ Soc. Bras. de Arborização Urbana 


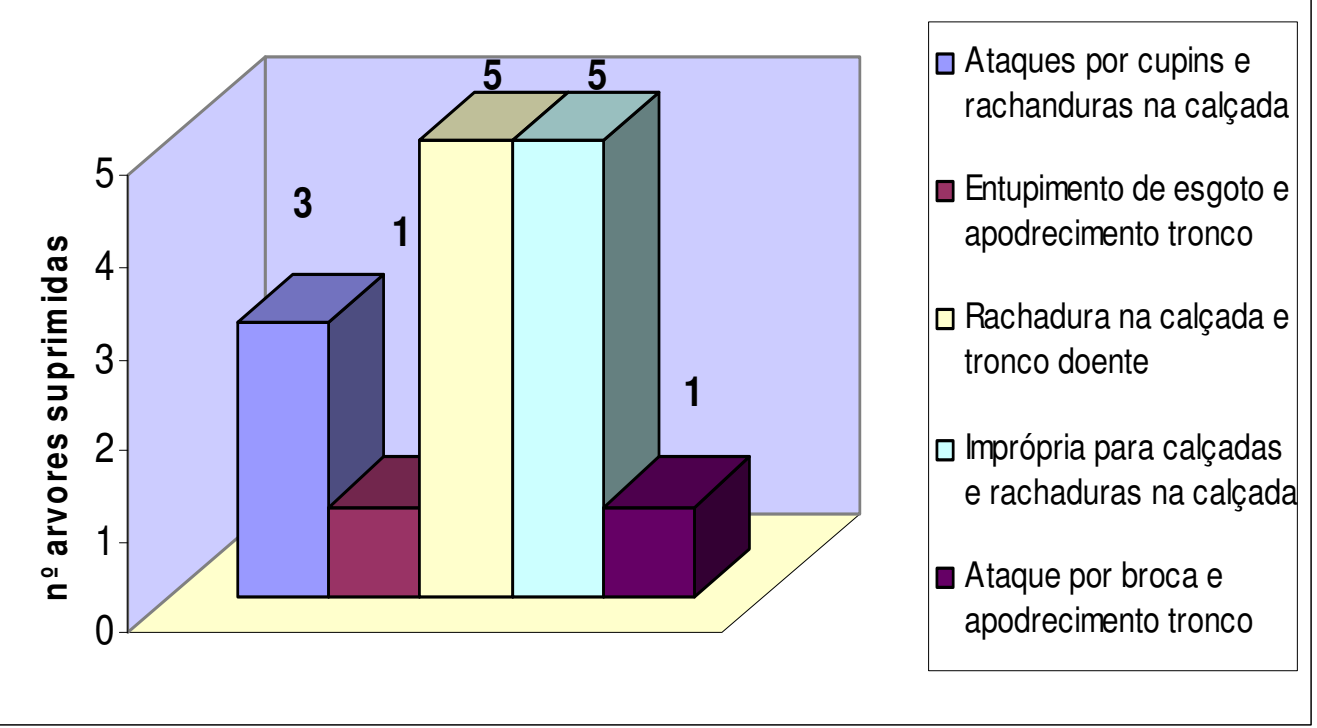

Figura 3: Fatores associados que levaram a supressão da arborização urbana no município de Itapira em 2009.

Figure 3: Related factors that led to the suppression of urban trees in the town of Itapira in 2009.

Nos resultados obtidos é possível observar um número significativo de árvores suprimidas devido a rachaduras nas calçadas dentre os motivos isolados e/ou fatores associados corroborando com o estudo de Ribeiro (2009), descrevendo que a maioria dos danos causados nas calçadas muitas vezes ocorre por causa de um plantio inadequado, onde é deixado um espaço pequeno e/ou por falta de orientação dos moradores, esquecendo que a muda depois de plantada vai crescer tendendo a seguir o tamanho da copa, figuras 2 e 3.

Segundo Almeida e Barbosa (2010), quando os moradores plantarem uma árvore na calçada, devem ser instruídos quanto às espécies mais indicadas e suas características, locais apropriados para adquirir as mudas, tutoramento, cuidados necessários e, principalmente, quanto à importância da arborização urbana das cidades.

Um dos problemas referentes à arborização de vias públicas sem a realização de um prévio planejamento é o plantio de espécies de grande porte em lugares inadequados. Este procedimento é muito comum nas cidades brasileiras, causando, muitas vezes, sérios prejuízos, como rompimento de fios de alta-tensão, interrupções no fornecimento de energia elétrica, entupimento em redes de esgoto, obstáculos para circulação e acidentes 
envolvendo pedestres, veículos ou edificações (FARIA et al., 2007; ALMEIDA e BARBOSA, 2010), fator que aumenta consideravelmente os pedidos de corte pelos munícipes.

Assim, na escolha das espécies para arborização urbana, devem-se avaliar alguns critérios, como o ritmo e exigências para o crescimento, o tipo de copa, porte, folhagem, as flores e frutos, problemas de toxidez, rusticidade, resistência e também derrama natural. Ainda outros parâmetros devem ser verificados, tais como; a largura da calçada, clima, solo e umidade da localidade são variáveis que se mostram importantes na avaliação e procedimentos de seleção da espécie botânica (SILVA, 2005).

\section{CONCLUSÃO}

Por meio da análise das informações obtidas sobre as principais causas de supressão da arborização urbana no município de Itapira-SP ocorrido no ano de 2009, os resultados apontam uma deficiência no planejamento da implantação da arborização nos bairros com a escolha de arvores impróprias para calçadas e passeios públicos, ignorando suas características e os comportamentos que lhe são próprios, proporcionando um aumento do risco de queda e interferência na estrutura urbana.

\section{CONSIDERAÇÕES FINAIS}

- Com o mapeamento das supressões arbóreas por bairro, pode-se direcionar o desenvolvimento de projetos de educação ambiental visando uma maior conscientização da população para a importância da arborização urbana e a melhoria da qualidade de vida.

- É preciso planejar o plantio das árvores no perímetro urbano tomando como base os critérios técnicos adequados de forma a reduzir os danos materiais (danos a muros e calçadas) para que haja, de fato, uma redução do numero de supressões arbóreas e que a população perceba os benefícios da arborização urbana visando a melhoria do ambiente urbano, tanto para a árvore como para a população. 


\section{REFERÊNCIAS BIBLIOGRÁFICAS}

ALVES, S. M.; GOUVEIA, V. V. Atitudes em Relação à Arborização Urbana: Uma Contribuição da Psicologia Ambiental para a Qualidade de Vida Urbana. Laboratório de Psicologia Ambiental, Vol. 4, n. 6, Brasília, 1995.

ALMEIDA, J. R.; BARBOSA, C. G. Diagnóstico da Arborização Urbana da Cidade de Cacoal-Ro. Revista da Sociedade Brasileira de Arborização Urbana v.5, n.1, 2010, p.61-81.

BORTOletO, S; SILVA FILHO, D. F; LIMA, A. M L. P. Prioridades de Manejo para a Arborização Viária da Estância de Águas de São Pedro-SP. Revista da Sociedade Brasileira de Arborização Urbana. v.1, n. 1, 2006.p.73.

COLETTO, E. P.; MÜLLER, N. G.; WOLSKI, S. S. Diagnóstico da Arborização das Vias Públicas do Município de Sete de Setembro - RS Revista da Sociedade Brasileira de Arborização Urbana, v.3, n.2, jun. 2008, p.110-122

FARIA, J. L. G.; MONTEIRO, E. A.1, FISCH, S. T. V. Arborização de Vias Públicas do Município de Jacareí - SP Revista da Sociedade Brasileira de Arborização Urbana, v.2, n.4, dez. 2007, p. 20-33.

GRAZIANO, T. T. Viveiros Municipais. Departamento de Horticultura - FCAVJ - UNESP, 1994.

IBGE <www.ibge.gov.br/home/estatistica/populacao/condicaodevida/pnsb/pnsb.pdf> Acesso em 22 de dezembro, 2009.

Instituto de Pesquisas Tecnológicas do Estado de São Paulo S.A. - IPT. <http://www.ipt.br> Acesso no mês de janeiro de 2007.

MÜLLER, J. Orientação básica para manejo da arborização urbana. Edições FAMURS. Porto Alegre: Nova Prova, 1998.

PREFEITURA Municipal de Itapira. Revista da Cidade. Disponível em:

<http://www.itapira.sp.gov.br/institucional/revista/revista sobre cidade itapira.pdf>. Acesso em: 16 abril 2007.

RIBEIRO, F. A. B. S. Arborização Urbana em Uberlândia: Percepção da População Revista da Católica, Uberlândia, v. 1, n. 1, p. 224-237, 2009

RODRIGUES, C. A. G.; BEZERRA, B. C.; ISHII, I.H.; CARDOSO, E. L.; SORIANO, B. M. A.; OLIVEIRA, H. Arborização Urbana e Produção de Mudas de Essências Florestais Nativas em Corumbá, MS, Emprapa Pantanal, Corumbá, 2002

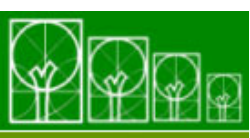

S $\cdot \mathbf{B} \cdot \mathbf{A} \cdot \mathbf{U}$ Soc. Bras. de Arborização Urbana 
RODOLFO JUNIOR, F.; MELO, R. R.; CUNHA, T. A.; STANGERLIN, D. M. Análise da arborização urbana em bairros da cidade de Pombal no Estado da Paraíba Revista da Sociedade Brasileira de Arborização Urbana, v.3, n.4, p.3-19, 2008.

ROSSETTI, A. I. N.; PELLEGRINO, P. R. M.; TAVARES, A. R. AS Árvores e suas Interfaces no Ambiente Urbano Revista da Sociedade Brasileira de Arborização Urbana, v.5, n.1, p.1-24, 2010

SANTANA, J.R. F.; SANTOS, G.M.M. Arborização do campus da UEFS: exemplo a ser seguido ou um grande equívoco? Sitientibus, n.20, p.103-107, 1999.

SETZER, J. Atlas Climático do Estado de São Paulo. Secretaria da Agricultura. São Paulo, 1976.

SILVA, L. F. da Situação da arborização Viária de espécies para os bairros Antônio Zanaga I e II, da Cidade de Americana/SP. 2005. 80f. Dissertação (Mestrado em Agronomia, área de concentração Fitotecnia) - Escola Superior de Agricultura "Luis de Queiroz", Universidade de São Paulo, Piracicaba, 2005.

SILVA FILHO, D.F., PIZZETTA, P. U. C., ALMEIDA, J. B. S.A. Banco de dados relacional para cadastro, avaliação e manejo da arborização em vias públicas. Revista Árvore, v.26, n.5, p.629-642. 2002.

SILVA, E. M., SILVA, A. M., MELO, P. H., BORGES, S. S., LIMA, S. C. Estudo da Arborização Urbana do Bairro Mansour, na Cidade de Uberlândia-Mg. Caminhos de Geografia, v.3, n.5, Fev/ 2002.

TEIXEIRA, I. F. Análise qualitativa da arborização de ruas do Conjunto Habitacional Tancredo Neves, Santa Maria - RS. Ciência Florestal, Santa Maria, v. 9, n. 2, p. 9-21, 1999. 